\title{
Закономерности формирования железистых минеральных вод курорта «Марциальные воды» (Карелия) по благородным газам $\left({ }^{3} \mathrm{He} /{ }^{4} \mathrm{He},{ }^{20} \mathrm{Ne} /{ }^{4} \mathrm{He}\right)$
}

\author{
Бородулина Г.С. ${ }^{1}$, Каменский И.Л. ${ }^{2}$, Скиба В.И. ${ }^{2}$, Токарев И.В. ${ }^{3}$ \\ ${ }^{1}$ Институт водных проблем Севера Карельского научного иентра РАН, Петрозаводск, \\ bor6805@yandex.ru \\ 2 Геологический институт КНЦ РАН, Anamumbl, skiba@geoksc.apatity.ru \\ ${ }^{3}$ Санкт-Петербургский государственный университет, Научный парк, РЦ РДМИ, \\ tokarevigor@gmail.com
}

Аннотация. Железистые минеральные воды (курорт «Марциальные воды», Карелия) по изотопному составу гелия $\left({ }^{3} \mathrm{He} /{ }^{4} \mathrm{He}\right)$ и неон/гелиевому отношению $\left({ }^{20} \mathrm{Ne} /{ }^{4} \mathrm{He}\right)$ идентифицируются как смесь подземных вод различного возраста. Тритий/гелий-3 возраст молодой компоненты составлял около 34 лет (опробование 1989 г.) и 45 лет (2013 г.). Доля «старых» вод между двумя опробованиями уменьшилась, изотопный состав воды приблизился к современным атмосферным осадкам, изменились также содержания других изотопных трассеров $\left({ }^{234} \mathrm{U} /{ }^{238} \mathrm{U},{ }^{13} \mathrm{C}\right)$, свидетельствуя о том, что минеральные воды, по-видимому, обрели практически инфильтрационный облик.

Ключевые слова: изотопный состав гелия, неон/гелиевое отношение, тритий/гелий-3 датирование.

\section{Formation of ferruginous mineral waters of the "Marcial Waters" resort (Karelia) according to noble gases $\left({ }^{3} \mathrm{He} /{ }^{4} \mathrm{He},{ }^{20} \mathrm{Ne} /{ }^{4} \mathrm{He}\right)$}

\author{
Borodulina G.S. ${ }^{1}$, Kamensky I.L. ${ }^{2}$, Skiba V.I. ${ }^{2}$, Tokarev I.V. ${ }^{3}$ \\ ${ }^{1}$ Northern Water Problems Institute of the Karelian Research Centre of the Russian Academy of Sciences, \\ Petrozavodsk,bor6805@yandex.ru \\ ${ }^{2}$ Geological Institute, Kola Science Centre, Russian Academy of Sciences, Apatity, skiba@geoksc.apatity.ru \\ ${ }^{3}$ Resource Center for X-ray Diffraction Studies at the Research park of St. Petersburg State University, \\ St.Petersburg,tokarevigor@gmail.com
}

\begin{abstract}
Ferrous mineral waters (Marcial Waters health resort, Karelia) are identified by the helium isotopic composition $\left({ }^{3} \mathrm{He} /{ }^{4} \mathrm{He}\right)$ and neon / helium ratio $\left({ }^{20} \mathrm{Ne} /{ }^{4} \mathrm{He}\right)$ as a mixture of groundwater of different ages. The tritium/ helium-3, age of the young component was about 34 years (sampling of 1989) and 45 years (2013). Abundance of "old" waters between the two tests decreased, the isotope composition of water shifted to modern precipitations, and the content of other isotopic tracers $\left({ }^{234} \mathrm{U} /{ }^{238} \mathrm{U},{ }^{13} \mathrm{C}\right)$ changed indicating that the mineral waters apparently acquired an almost meteoric composition.
\end{abstract}

Key words: helium isotopes, neon/helium ratio, tritium/helium-3 dating.

Первый русский курорт «Марциальные воды» организован при личном участии Петра I, и в 2019 г. здравница отметила 300 лет. В современном виде курорт действует с 1964 г. и использует в лечебно-питьевых целях высокожелезистые сульфатные подземные воды (выделены в самостоятельный гидрохимический тип), разгружающиеся самоизливом из четырех скважин ${ }^{1}$. Воды скважин сходны по химическому типу, но отличаются по минерализации и концентрации железа. От скважины 1-к к скважине 4-к наблюдается увеличение минерализации воды от 0.25 до 0.92 г/л и рост концентрации железа от 14 до 96 мг/л.

Длительный, но нерегулярный ряд наблюдений, а также результаты химических анализов разной степени надежности не позволяют составить единое представление о формировании Марциальных вод и их состоянии в изменяющихся условиях (Бородулина и др., 2019). В 2018 г. начаты регулярные режимные наблюдения по четырем эксплуатационным скважинам, включающие:

\footnotetext{
${ }^{1}$ Первоначально вода отбиралась из каптированных родников, которые исчезли после бурения скважин.
} 

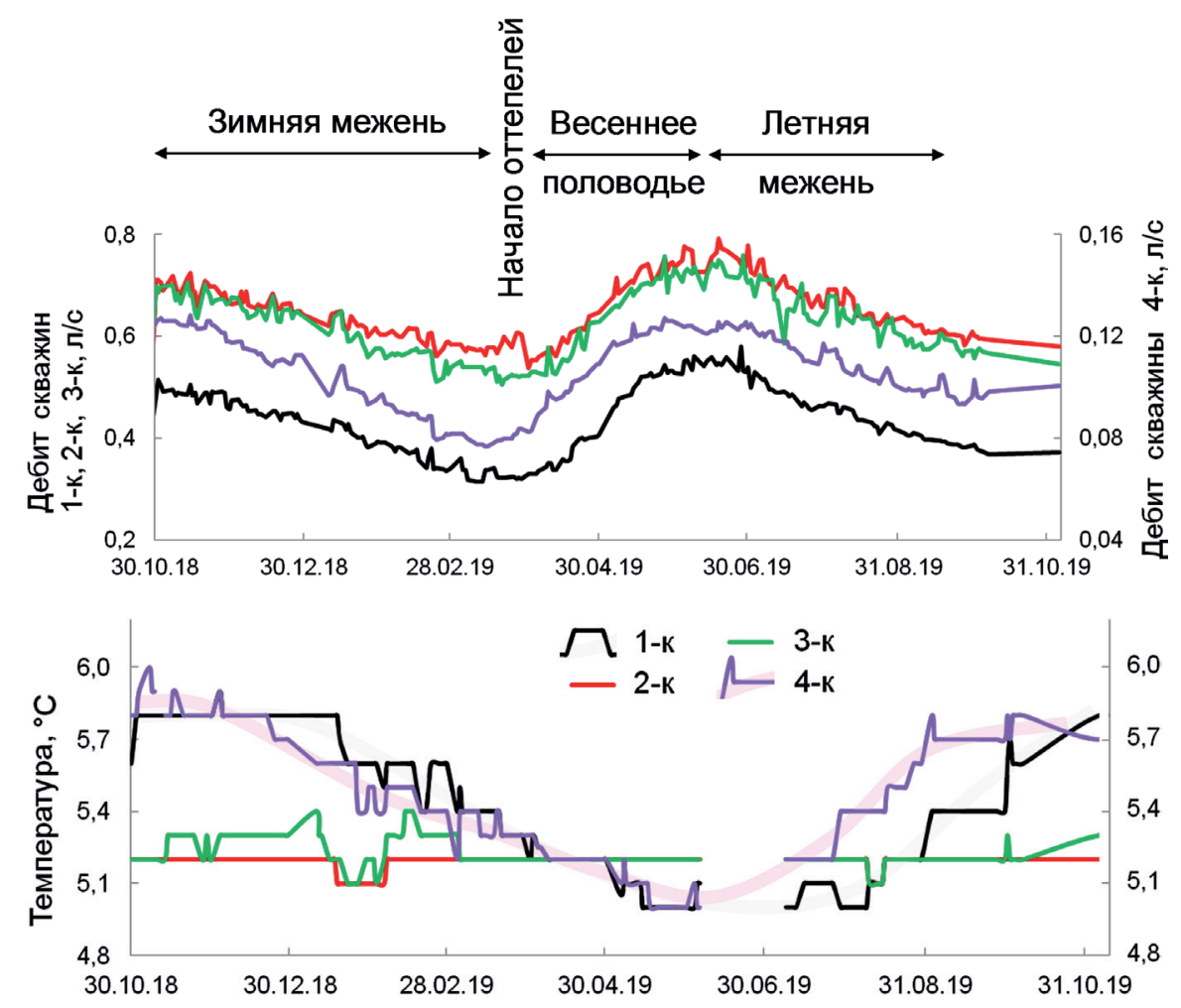

Рис. 1. Дебит и температура минеральных вод.

Fig. 1. The well flow rate and temperature of the mineral waters.

- ежемесячное определение химического и изотопного состава воды;

- ежесуточное измерение температуры и расходов воды.

Дебит скважин колеблется синхронно, достигая минимума в зимнюю межень и возрастая вслед за весенним половодьем. Температура воды в скважинах 1-к и 4-к понижается с ростом дебита (рис. 1).

Минерализации воды практически постоянна в скважине 1-к. Наибольшая амплитуда колебаний наблюдается в скважине 4-к, имеющей минимальный дебит, при этом график вариаций электропроводности, по-видимому, смещен по фазе относительно графика для дебитов в сторону запаздывания (рис. 2). Вариации химического состава воды не соответствуют устоявшемуся мнению, что максимальная минерализация и содержания Fе отмечается в меженные периоды.



Рис. 2. Изменение электропроводности воды в скважине 4-к.

Fig. 2. The electrical conductivity of water from the well 4-k.

Активности трития $\left({ }^{3} \mathrm{H}\right.$, рис. 3$)$ в минеральной воде снижаются во времени вслед за уменьшением его концентраций в атмосферных осадках, при сохранении, в целом, соотношения его содержаний между скважинами (наиболее высокие - в 1-к и наиболее низкие - в 4-к скважине).

Изотопный состав гелия $\left({ }^{3} \mathrm{He} /{ }^{4} \mathrm{He}\right)$ и неон/гелиевое отношение $\left({ }^{20} \mathrm{Ne} /{ }^{4} \mathrm{He}\right)$ указывает, что минеральные воды представляют собой смесь подземных вод различного возраста (рис. 4, табл. 1). Условно назовем их «молодая» (возраст менее 100 лет) и «древняя» (возраст свыше 500 лет) компоненты. Присутствие молодой компоненты диагностируется по заметным концентрациям трития и тритигенного гелия-3 (последнее видно из роста отношения ${ }^{3} \mathrm{He} /{ }^{4} \mathrm{He}$ по сравнению с характерным для инфильтрационных вод (Kamensky 


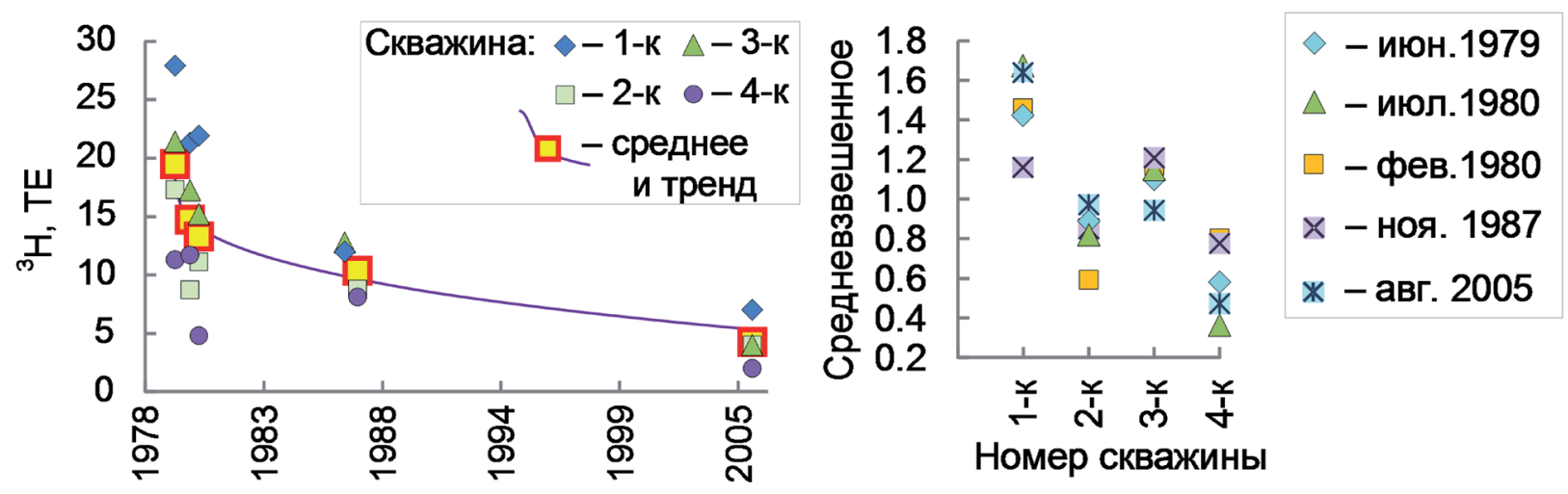

Рис. 3. Содержания трития в Марциальных водах (Ресурсы..., 1987; Токарев и др., 2008): хронологический график (слева показано также текущее среднее для четырех скважин), (справа - нормированное на среднее для каждого из моментов опробования.

Fig. 3. Tritium content in "Marcial Waters" (Resources ..., 1987; Tokarev et al., 2008): left panel is a chronological graph (the current average for four wells is also shown), right panel is normalized to the average for each testing.

et al., 1991). Вклад древней компоненты диагностируется по пониженному (относительно инфильтрационных вод) отношению ${ }^{20} \mathrm{Ne} /{ }^{4} \mathrm{He}$. Возраст древней компоненты неизвестен, однако можно предположить, что он достаточно велик - первые десятки тысяч лет, как это установлено работами в северо-западном регионе РФ (Воронюк и др., 2016; Токарев и др., 2008; Kamensky et al., 1991; Tokarev et al., 2019). Тогда для древней компоненты можно принять, что ${ }^{3} \mathrm{He} /{ }^{4} \mathrm{He} \rightarrow 0$ и ${ }^{20} \mathrm{Ne} /{ }^{4} \mathrm{He} \rightarrow 0$.

В молодых инфильтрогенных водах происходит рост отношения ${ }^{3} \mathrm{He} /{ }^{4} \mathrm{He}$ вследствие накопления тритигенного гелия-3, а отношение ${ }^{20} \mathrm{Ne} /{ }^{4} \mathrm{He}$ остается практически постоянным. На диаграмме ${ }^{3} \mathrm{He} /{ }^{4} \mathrm{He} \div{ }^{20} \mathrm{Ne} /{ }^{4} \mathrm{He}$ изотопные координаты молодых вод определяются графически как точка пересечения линии смешения «молодой» и «древней» компонент с коридором эволюции изотопного состава гелия в молодых водах. В нашем случае на диаграмме ${ }^{3} \mathrm{He} /{ }^{4} \mathrm{He} \div{ }^{20} \mathrm{Ne} /{ }^{4} \mathrm{He}$ линиями смешения является прямые, выходящие из начала координат (изотопные координаты «древних» вод ${ }^{3} \mathrm{He} /{ }^{4} \mathrm{He}=0$ и $\left.{ }^{20} \mathrm{Ne} /{ }^{4} \mathrm{He}=0\right)$ и проходящие через точки с измеренным изотопным составом благородных газов. На рис. 4 линии смешения «молодой» и «древней» компонент построены для максимального и минимального из измеренных отношений ${ }^{3} \mathrm{He} /{ }^{4} \mathrm{He}$ в смешанных водах. Видно, что в 1989 г. состав благородных газов в минеральных водах всех скважин был более однороден, чем в 2013 г.

С учетом измеренных концентраций трития (табл. 2) и расчета содержаний тритигенного гелия-3 был ориентировочно оценен возраст молодой компоненты минеральной воды. Для опробова-

Рис. 4. Изотопный состав гелия и неон/гелиевое отношение в Марциальных водах на различные моменты времени и расчет изотопных координат молодых вод:

1 - линия накопления терригенного гелия в древних подземных водах; 2, 3, 4 - линии смешения молодых и древних вод; 5 - изотопные координаты инфильтрационных вод; 6 - коридор эволюции изотопного состава молодых вод и расчетные изотопные координаты молодых вод для Марциальных вод.

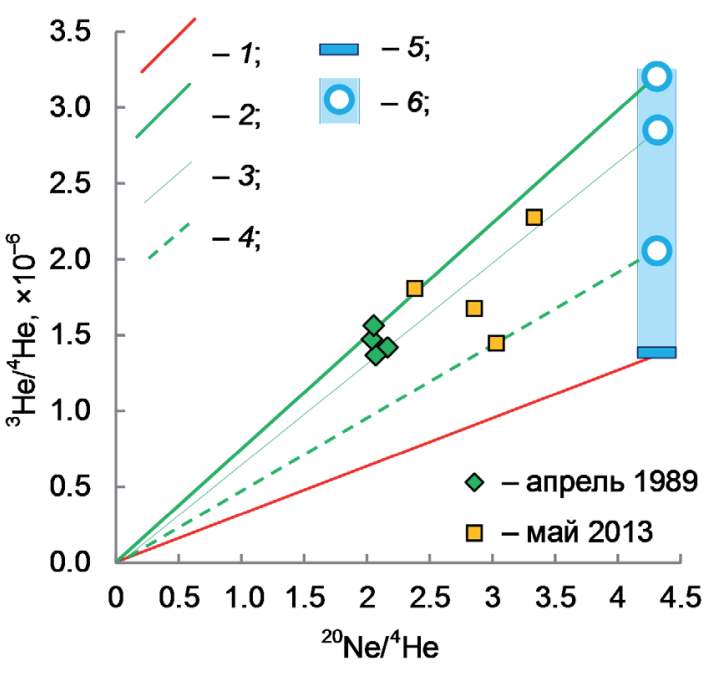

Fig. 4. Correlations between the ${ }^{3} \mathrm{He} /{ }^{4} \mathrm{He}$ and ${ }^{20} \mathrm{Ne} /{ }^{4} \mathrm{He}$ ratios in "Marcial Waters" and the calculation of the noble gases isotope composition of young waters:

1 - line of accumulation of terrigenous helium in fossil groundwater; 2, 3, 4 - mixing lines of young and fossil waters; 5 - isotope composition of noble gases of the recharge water; 6 - evolution of the helium isotope composition in young water and calculated isotopic coordinates of young waters. 
ния 1989 г. при относительно узком диапазоне возрастов молодых вод $\tau=33-35$ лет время поступления инфильтрационной воды в систему - это, ориентировочно, середина $1950^{-х}$ годов. Расчетные начальные содержания трития - около 70 ТЕ не противоречат наблюдениям (Виноградов и др., 1968; Вакуловский и др., 1978). Для опробования 2013 г. при заметно большем разбросе возрастов $\tau=42-49$ лет время поступления инфильтрационной воды в систему - это вторая половина 1960-х годов, а расчетные начальные содержания трития составляют около 45-65 ТЕ. При этом доля «старых» вод уменьшилась, на что указывает рост неон/гелиевого отношения.

Примерно в эти же годы произошло существенное изменение изотопного состава минеральной воды (содержаний дейтерия и кислорода-18), который из значительно фракционированного в 1979 г. (сдвиг вправо относительно локальной линии метеорных вод) стал идентичен метеорным водам в 2005 г. (Ресурсы..., 1987; Токарев и др., 2008; Токарев и др., 2015). Одновременно уменьшилось общее содержание гелия, снизилось отношение ${ }^{234} \mathrm{U} /{ }^{238} \mathrm{U}$ и утяжелился изотопный состав растворенных форм углерода $\left(\delta^{13} \mathrm{C}\right)$.

Указанные изменения можно объяснить, как минимум, двумя факторами.

1. Расширением области современного питания вследствие перехода в 1964 г. к эксплуатации месторождения с помощью скважин.

2. Увеличением интенсивности инфильтрации вследствие строительства в $60^{-х}$ годах санатория и поселка в области питания (за счет планировки территории, организации фундаментов, дорог, траншей под водопровод и канализацию и т.п.).

Таблица 1. Изотопный состав благородных газов Марциальных вод в 1987, 1989, 2013.

Table 1. ${ }^{3} \mathrm{He} /{ }^{4} \mathrm{He}$ and ${ }^{20} \mathrm{Ne} /{ }^{4} \mathrm{He}$ ratios in "Marcial Waters" in 1987, 1989, 2013.

\begin{tabular}{|c|l|c|c|}
\hline Well ID & Дата отбора & ${ }^{3} \mathrm{He} /{ }^{4} \mathrm{He} \times 10^{-6}$ & ${ }^{4} \mathrm{He} /{ }^{20} \mathrm{Ne}$ \\
\hline \multirow{2}{*}{$1-\kappa$} & April, 1989 & 1.413 & 0.462 \\
\cline { 2 - 4 } & May, 2013 & 2.270 & 0.300 \\
\hline \multirow{2}{*}{$2-\kappa$} & April, 1989 & 1.360 & 0.483 \\
\cline { 2 - 4 } & May, 2013 & 1.800 & 0.420 \\
\hline \multirow{3}{*}{$3-\kappa$} & December, 1987 & 1.440 & 0.390 \\
\cline { 2 - 4 } & April, 1989 & 1.465 & 0.490 \\
\cline { 2 - 4 } & April, 1989 & 1.458 & 0.372 \\
\cline { 2 - 4 } 4-к & May, 2013 & 1.440 & 0.330 \\
\hline \multirow{2}{*}{} & April, 1989 & 1.557 & 0.487 \\
\cline { 2 - 4 } & May, 2013 & 1.670 & 0.350 \\
\hline
\end{tabular}

Таблица 2. Содержания трития в Марциальных водах $\left({ }^{3} \mathrm{H}, \mathrm{TE}\right)$.

Table 2. Tritium concentration in "Marcial Waters" ( $\left.{ }^{3} \mathrm{H}, \mathrm{TU}\right)$.

\begin{tabular}{|c|c|c|c|c|c|}
\hline Well ID & June, 1979 & February, 1980 & July, 1980 & November, 1987 & August, 2005 \\
\hline 1-К & 27.9 & 21.3 & 21.9 & 12 & $7 \pm 2$ \\
\hline 2-К & 17.3 & 8.7 & 11.1 & 8.8 & $4 \pm 2$ \\
\hline 3-К & 21.4 & 17.2 & 15.2 & 12.5 & $4 \pm 2$ \\
\hline 4-К & 11.3 & 11.7 & 4.8 & 8.1 & $2 \pm 2$ \\
\hline
\end{tabular}

Работа выполнена при финансовой поддержке гранта РФФИ (проект № 18-45-100004).

\section{Литература}

1. Бородулина Г.С., Токарев И.В., Левичев М.А. Первому русскому курорту - 300 лет. История изучения «Марциальных вод» // Вопросы курортологии, физиотерапии и лечебной физической культуры. 2019. № 4. T. 96. С. 76-82. DOI 10.17116/kurort20199604176.

2. Вакуловский С.М., Воронцов А.И., Катрич А.И. и др. Тритий в атмосферных осадках, реках и морях, омывающих территорию Советского Союза // Атомная энергия. 1978. Т. 44. Вып. 5. С. 432-446. 
3. Виноградов А.П., Девирц А.Л., Добкина Э.И. Современное состояние трития в природных водах // Геохимия. 1968. № 10. С. 1147-1152.

4. Воронюк Г.Ю., Бородулина Г.С, Крайнюкова И.А., Токарев И.В. Водообмен в краевых частях Балтийского щита и прилегающих артезианских бассейнах по изотопным и химическим данным (научные и прикладные аспекты). Карельский перешеек // Труды Карельского научного центра. Серия «Лимнология». 2016. № 9. С 46-56. DOI: 10.17076/lim322.

5. Ресурсы и геохимия подземных вод Карелии. Петрозаводск: Карельский филиал АН СССР. 1987. 151 с.

6. Токарев И.В., Бородулина Г.С., Блаженникова И.В., Авраменко И.А. Условия формирования железистых минеральных вод по изотопно-геохимическим данным (курорт «Марциальные воды», Карелия) // Геохимия. 2015. №1. С. 88-91. DOI: 10.7868/S0016752514110090.

7. Токарев И.В., Бородулина Г.С., Каюкова Е.П. Поляков В.А., Варнакова Ю.В., Жданов С.В., Маркова Т.В. Исследование подземных вод в отдельных районах Карелии изотопно-геохимическими методами. Вестник СПбГУ. Серия 7 «Геология и география». 2008. № 2. С. 25-36.

8. Kamensky I.L., Tokarev I.V. and Tolstikhin I.N. ${ }^{3} \mathrm{H}-{ }^{3} \mathrm{He}$ dating: A case for mixing of young and old groundwaters // Geochemica et Cosmochemica Acta. 1991. V. 55. P. 2895-2899.

9. Tokarev I.V., Borodulina G.S., Subetto D.A., Voronyuk G.Y., Zobkov M.B. Fingerprint of the geographic and climate evolution of the Baltic-White Sea region in the Late Pleistocene-Holocene in groundwater stable isotopes $\left({ }^{2} \mathrm{H},{ }^{18} \mathrm{O}\right)$. Quaternary International. 2019. V. 524. P. 76-85. DOI: 10.1016/j.quaint.2019.03.022. 